\title{
S. macrurus myogenic regulatory factors (MRFs) induce mammalian skeletal muscle differentiation; evidence for functional conservation of MRFs
}

\author{
HYUN-JUNG KIM ${ }^{1}$, ROBERT GÜTH ${ }^{1}$, COLLEEN B. JONSSON ${ }^{2}$ and GRACIELA A. UNGUEZ*,1 \\ ${ }^{1}$ Department of Biology, New Mexico State University, Las Cruces, NM, USA and \\ ${ }^{2}$ Department of Biochemistry and Molecular Biology, Southern Research Institute, Birmingham, AL, USA
}

\begin{abstract}
The current-producing cells of the electric organ, i.e., electrocytes, in Sternopygus macrurus derive from skeletal muscle fibers. Mature electrocytes are not contractile, but they do retain some muscle proteins, are multinucleated, and receive cholinergic innervation. Electrocytes express the myogenic regulatory factors (MRFs) MyoD, myogenin, Myf5 and MRF4 despite their incomplete muscle phenotype. Although $S$. macrurus MRFs share functional domains which are highly conserved and their expression is confined to the myogenic lineage, their capability to induce the muscle phenotype has not been determined. To test the functional conservation of $S$. macrurus MRFs to transcriptionally activate skeletal muscle gene expression and induce the myogenic program, we transiently over-expressed $S$. macrurus MyoD (SmMyoD) and myogenin (SmMyoG) in mouse C3H/10T1/2 and NIH3T3 embryonic cells. RT-PCR and immunolabeling studies showed that SmMyoD and SmMyog can efficiently convert these two cell lines into multinucleated myotubes which expressed differentiated muscle markers. The levels of myogenic induction by SmMyoD and SmMyog were comparable to those obtained with mouse MRF homologs. Furthermore, SmMyoD and SmMyoG proteins were able to induce mouse MyoD and myogenin in $\mathrm{C} 3 \mathrm{H} / 10 \mathrm{~T} 1 / 2$ cells. We conclude that $S$. macrurus MRFs are functionally conserved as they can transcriptionally activate skeletal muscle gene expression and induce the myogenic program in mammalian non-muscle cells. Hence, these data suggest that the partial muscle phenotype of electrocytes is not likely due to differences in the MRF-dependent transcriptional program between skeletal muscle and electric organ.
\end{abstract}

KEY WORDS: MyoD, myogenin, differentiation, electric fish, skeletal muscle

\section{Introduction}

Skeletal muscle gene expression is controlled largely by the MyoD family of basic-helix-loop helix myogenic regulatory factors (MRFs), which includes MyoD, myogenin, Myf5, and MRF4 (Emerson, 1990; Weintraub, 1993). MRFs encode structurally related transcription factors that bind to E-box consensus promoter elements (CANNTG) (Emerson, 1990; Fujisawa-Sehara et al., 1992; Weintraub, 1993) and are essential in the differentiation and commitment of cells to the muscle phenotype during development. Their role in the differentiation and commitment of cells to the skeletal muscle lineage is well established based on genetic studies demonstrating that myogenesis is severely deficient when
MRF genes are inactivated (Nabeshima et al., 1993; Rudnicki et al., 1993), and expression studies showing that MRFs can activate the myogenic program in non-muscle cells (Weintraub et al., 1989; Choi et al., 1990; Delfini and Duprez, 2004). Moreover, the activation of many muscle-specific genes including cytoskeletal, sarcomeric, metabolic, and cell signaling proteins is known to be under the transcriptional regulation of MRFs (Simon and Burden, 1993; Shield et al., 1996; Lin et al., 1991; Gramolini and Jasmin, 1999; Kraner etal., 1999; Wheeler etal., 1999; Angus et al., 2001;

\footnotetext{
Abbreviations used in this paper: $\mathrm{EO}$, electric organ; $\mathrm{MRF}$, myogenic regulatory
} factor; MyoG, myogenin; Sm, Sternopygus macrurus.

\footnotetext{
*Address correspondence to: Graciela A. Unguez. Department of Biology, Foster Hall, New Mexico State University, Las Cruces, NM 88003, USA. Tel: +1-575-646-7963. Fax: +1-505-646-5665. e-mail: gunguez@nmsu.edu
} 
Li and Capetanaki, 1993; Marsh et al., 1998).

Although MRFs can activate the myogenic program, the presence of MRFs does not ensure the full expression of the skeletal muscle program. In mammals, myoid cells of the thymus (Grounds etal., 1992), myofibroblasts (Mayer and Leinwand, 1997), and the electrical conductive cells of the heart (Takebayashi-Suzuki et al., 2001) express MyoD and/or myogenin yet these cells do not display a full muscle phenotype. A non-mammalian cell in which the expression of MRFs does not correlate with the level to which the myogenic program is manifested is the electrocyte, i.e., the current-producing cell of the electric organ in electric fishes. In all electric fish species known to date, mesodermal cells initially differentiate into myoblast-like cells that subsequently form myotubes. Conversion of these myotubes to mature electrocytes is characterized by the disassembly of sarcomeric structures, down-regulation of sarcomeric proteins, the replacement of myofibrils with amorphous material, relocation of many organelles to the periphery, and changes in cell size and shape (Bennett, 1970).

In the gymnotiform Sternopygus macrurus, mature electrocytes are similar to their muscle precursors in that they are multinucleated, express proteins common to muscle cells such as desmin, talin, acetylcholine receptors (AChRs), $\alpha$-actin, $\alpha$-actinin, dystrophin, and titin (Patterson and Zakon, 1993; Kim etal., 2004; Cuellar et al., 2006) and are innervated at a single endplate
(Bennett, 1970; Unguez and Zakon, 1998). However, mature electrocytes do not contain sarcomeres, sarcoplasmic reticulum, or T-tubules, nor do they contain tropomyosin, myosin heavy chains (MHCs), or troponin-T proteins (Patterson and Zakon, 1996; Cuellar et al., 2006). How a differentiated electrocyte can down-regulate some, but not all components of the muscle program is an intriguing problem in our current understanding of the transcriptional regulation of skeletal muscle genes.

The partial muscle phenotype of electrocytes and the wide phylogenetic distribution of the MyoD family across animal taxa (Atchley et al., 1994; Zhang et al., 1999) prompted us to clone all four MRFs from $S$. macrurus and examine their expression patterns in skeletal muscle and electric organ to determine if the electrocyte phenotype is due to an MRF expression pattern that correlates to the level and number of the muscle proteins maintained after its differentiation. Our data showed that the $\mathcal{S}$. macrurus genome contains MyoD, myogenin, Myf5, and MRF4 genes with predicted amino acid sequences that exhibit a high degree of sequence conservation in their functional domains (Kim et al., 2004; 2008) suggesting that $S$. macrurus MRFs likely have myogenic regulatory functions similar to those of their mammalian counterparts. Previous studies also revealed MRFs to be expressed in the myogenic lineage exclusively, but that their quantitative patterns in muscle fibers and electrocytes could not be used to predict the level to which each cell manifests the muscle
A

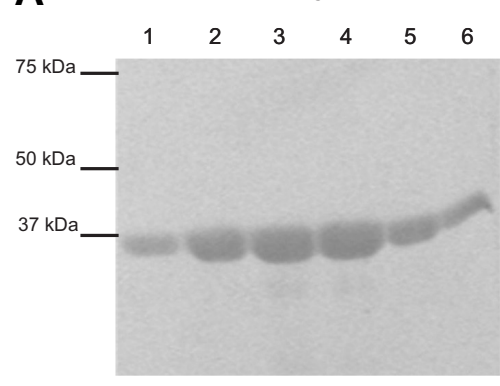

SmMyog

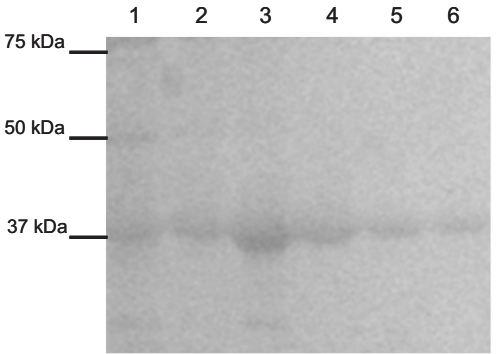

C MyoD

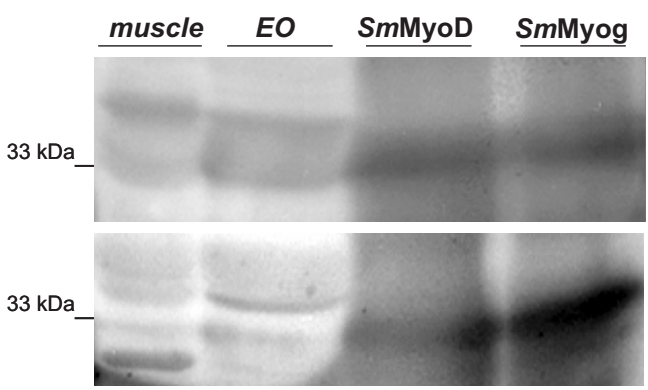

B

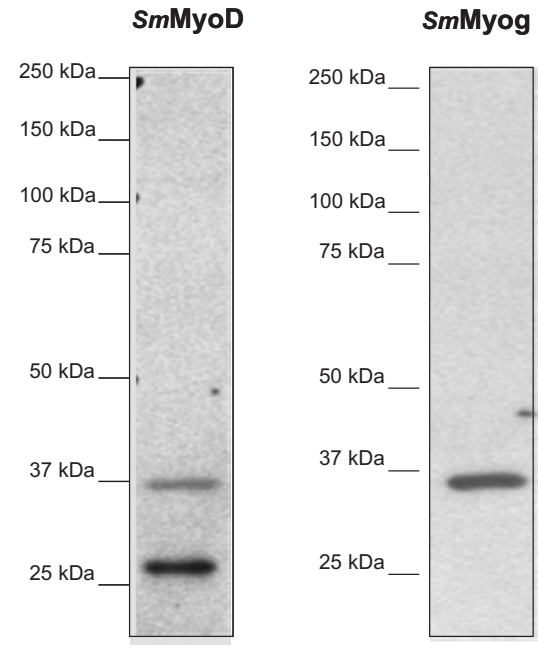

Fig. 1. Purification of Sternopygus macrurus MyoD and myogenin proteins and respective antibody reactivity to pure protein and protein extracts from skeletal muscle and electric organ tissues. (A) Purification of Sternopygus macrurus MyoD (SmMyoD) or myogenin (SmMyoG) protein. MyoD protein fractions eluted from the Ni2/NTA column were separated by 15\% SDS-PAGE and visualized with Coomassie blue staining. Lane numbers are indicated at the top of respective column fractions. Lanes 1 through 6 represent column fractions from the $\mathrm{pH} 4.5$ elution step. The major band in lanes 1 to 6 corresponds to the MyoD protein plus the HIS tag and thrombin cutting sequence. Myogenin protein fractions eluted from the Ni2/NTA column were separated by 15\% SDS-PAGE and visualized with Coomassie blue staining. Lane numbers are indicated at the top of respective column fractions. Lanes 1 through 6 represent column fractions from the $\mathrm{pH} 4.5$ elution step. The major band in lanes 1 to 6 corresponds to the myogenin protein plus the HIS tag and thrombin cutting sequence. (B) Western blot analysis of MyoD and myogenin protein purified from E. coli transformed cells carrying the expression vector $p E T 15 b$ is shown. Refolded MyoD and myogenin proteins were separated by $15 \%$ SDS-PAGE, transferred to Nytran membranes, and incubated with a 1:2000 dilution of rabbit antisera raised against MyoD or myogenin protein as described in Materials and Methods. (C) Western blots of protein extracts from skeletal muscle (muscle), electric organ (EO), and 10T1/2 cells transfected with S. macrurus MyoD (SmMyoD), or myogenin (SmMyoG) using the polyclonal antibodies specific to $S$. macrurus MyoD and myogenin. Abbreviation: epi, epithelium. 
program (Kim et al., 2004; 2008). These analyses however did not allow us to draw firm conclusions about MRF protein activity in $\mathcal{S}$. macrurus tissues.

In the present study, we tested the hypothesis that $S$. macrurus MRFs can induce mammalian non-muscle cells to adopt a skeletal muscle phenotype. We show that forced expression of $S$. macrurus MyoD (SmMyoD) or myogenin ( $S m M y o G$ ) in mouse embryonic stem cells (C3H/10T1/2 cells) and fibroblasts (NIH3T3 cells) results in the formation of multinucleated myotubes and up-regulation of sarcomeric proteins. The capacity of $\mathcal{S}$. macrurus MRFs to activate the myogenic program in non-muscle cells was comparable to that obtained with mouse MRFs. SmMyoD and SmMyoG also induced the expression of mouse MRF transcripts and proteins in $\mathrm{C} 3 \mathrm{H} / 10 \mathrm{~T} 1 / 2$ cells. Hence, these data are consistent with a functional conservation of an MRF-dependent transcriptional program of myogenesis in $\mathcal{S}$. macrurus, and suggest that the partial muscle phenotype of electrocytes is not likely due to differences in the MRF-dependent transcriptional program between skeletal muscle and electric organ.

\section{Results}

\section{Expression and purification of MyoD and myogenin pro- teins}

BL21 (DE3) cells harboring the expression vector pET15b MyoD or pET15b myogenin were grown overnight and total protein was extracted under denaturing conditions. Solubilized protein was subsequently subjected to separation by nickelaffinity chromatography. Following removal of the majority of the contaminating proteins, MyoD or myogenin protein was eluted from the resin by lowering the buffer $\mathrm{pH}$ to 4.5 . This released MyoD or myogenin protein into 6 fractions representing 6 column volumes (Fig. 1A). High yields of MyoD and modest levels of myogenin protein were extracted as shown in Fig. 1A. This one-step affinity purification yielded approximately $10-30 \mathrm{mg}$ of MyoD or myogenin protein from $500 \mathrm{ml}$ of cells.

Selected column fractions were pooled based on purity as visualized by Coomassie Blue staining and diluted to OD 0.2 at $595 \mathrm{~nm}$ for refolding. MyoD or myogenin protein fractions were pooled and sent to Cell Essentials, Inc. as antigens for the production of monoclonal antibodies in rabbits. Purified refolded MyoD and myogenin proteins were examined for reactivity against sera from MyoD or myogenin protein-inoculated rabbits by Western blot (Fig. 1B). Western blot analysis of purified MyoD protein reacted against two bands. The band of approximately $28 \mathrm{kDa}$ corresponds to the expected size of $S$. macrurus MyoD. The larger band most likely represents processing of the protein during refolding, since Coomassie Blue stained gels showed the presence of the lower dominant band during purification. The immunoanalysis with $\mathcal{S}$. macrurus antimyogenin showed one intense band corresponding to the expected size of approximately $33 \mathrm{kDa}$. These data suggest that the expressed MyoD and myogenin proteins were stable and not affected by endogenous bacterial proteases, and the rabbit antisera labels proteins of the expected size.

Skeletal muscle and electric organ homogenates from adult $S$. macruruswere probed with the MyoD and myogenin antibodies. MyoD labeled bands of approximately $33 \mathrm{kDa}$ and $37 \mathrm{kDa}$ in size in both muscle and electric organ (EO) (Fig. 1C). These two bands are somewhat larger in size than the predicted product of $\sim 28 \mathrm{kDa}$ based on the inferred protein sequence. Myogenin labeled a band in both skeletal muscle and EO that corresponded to the expected size of $\sim 33 \mathrm{kDa}$ (Fig. 1C). However, additional bands ranging between $\sim 28$ to $37 \mathrm{kDa}$ were also labeled with anti-myogenin in both tissues (Fig. 1C). To further test the specificity of the MyoD and myogenin antibodies, we performed immunoblots on cell lysates from 10T1/2 cells transfected with SmMyoD and SmMyoG. MyoD and myogenin antibodies labeled a single band of approximately 33 $\mathrm{kDa}$ in each of the cell lysates (Fig. 1C). In sum, the crossreactivity obtained with these antibodies in Western blots of purified proteins, muscle and EO tissue homogenates, and lysates of transfected cells with SmMyoD and SmMyoG suggests the detection of these two proteins and potentially their phosphorylated forms (Thayer et al., 1989).

\section{MyoD and myogenin immunolabeling of S. macrurus muscle and EO tissue}

In order to determine the expression pattern of MyoD and myogenin proteins in skeletal muscle fibers and electrocytes in $\mathcal{S}$. macrurus, we examined the immunolabeling obtained with antibodies specific against MyoD and myogenin of $\mathcal{S}$. macrurus. Tissue cryosections of adult fish tails immunoreacted with antiMyoD and anti-myogenin are shown in Fig. 2A and 2B, respectively. Immunolabeling with the anti-MyoD antibody was detected in nuclei of muscle fibers as verified by Hoechst staining (Fig. 2A; arrows). Some background staining was found along the perimeter of electrocyte, and most electrocyte nuclei were not immunolabeled with the anti-MyoD antibody. Myogenin immunolabeling was detected in nuclei of both electrocytes and muscle fibers in adult tails of $S$ macrurus as shown in Fig. $2 B$. 
These data suggest that MyoD and myogenin proteins are present in adult cells of the myogenic lineage in $S$. macrurus.

\section{Induction of the myogenic program in mammalian non- muscle cells by S. macrurus $M y o D$ and myogenin}

To determine whether SmMyoD and SmMyoG exhibit functional conservation in mammalian skeletal muscle differentiation, we tested the ability of SmMyoD and SmMyoG to induce mammalian non-muscle cells to adopt a myogenic phenotype. Specifically, we transiently transfected mouse embryonic 10T1/2 cells with vectors expressing either SmMyoD or SmMyoG and then tested for the presence of sarcomeric MHC by immunofluorescence staining. Exogenously expressed SmMyoD and SmMyoG proteins were detected one day after transfection (Fig. 3A, top panel). At 3 days after transfection, we observed elongated and often multinucleated cells with myotube-like morphology that contained sarcomeric MHC in their cytoplasm (Fig. 3A, bottom panel). Detection of MHC staining was not restricted to multinucleated cells, as mononucleated cells were also immunolabeled by the anti-MHC antibody (Fig. 3A, bottom panel). In contrast, $\mathrm{MHC}$ immunolabel was not detected in cells transfected with empty vectors (data not shown).

In parallel with transfections with $S$. macrurus MRFs, we transfected 10T1/2 cells with mouse MyoD and myogenin cDNA to compare the transfection and conversion of non-muscle cells with MRFs from different species (Fig. 3A). Based on cell counts, we found that $10-20 \%$ of the cells expressed MRF proteins from plasmids containing either mouse or $\mathcal{S}$. macrurus cDNAs. Transfection efficiencies obtained in this study that used mouse and fish MRF cDNAs fell within a range that is in agreement with that observed previously for mammalian MRFs (personal communication Stephen F. Konieczny). As evident by the number of cells with $\mathrm{MHC}$ immunolabel, the conversion of $10 \mathrm{~T} 1 / 2$ cells to a myogenic phenotype after transfection with mouse MyoD or myogenin cDNA was also comparable to the conversion of 10T1/ 2 cells when they were transfected with the $S$. macrurushomologs (data not shown). To more thoroughly characterize the myogenic induction of $10 \mathrm{~T} 1 / 2$ cells by $\mathcal{S}$. macrurus MRFs, expression of different differentiation muscle markers was examined using RTPCR to amplify mRNAs for fast MHC isoforms, tropomyosin and troponin-I (Table 1). Consistent with the immunofluorescence results, sarcomeric MHC transcripts were detected in MRF-

\section{TABLE 1}

HOMOLOGOUS PRIMERS USED FOR AMPLIFICATION OF MUSCLE-SPECIFIC GENE TRANSCRIPTS FROM TRANSFECTED CELLS

\begin{tabular}{|c|c|c|c|c|}
\hline Gene & Orientation & Primer sequence & $\begin{array}{l}\mathrm{Tm} \\
\left({ }^{\circ} \mathrm{C}\right) \mathrm{F}\end{array}$ & $\begin{array}{l}\text { PCR } \\
\text { roduct size }\end{array}$ \\
\hline $\begin{array}{l}\text { MyoD } \\
\text { (mouse) }\end{array}$ & $\begin{array}{l}\text { Forward } \\
\text { Reverse }\end{array}$ & $\begin{array}{l}\text { 5'- AGTGAATGAGGCCTTCGAGA -3' } \\
\text { 5'- CATCATGCCATCAGAGCAGT -3' }\end{array}$ & 53 & $259 \mathrm{bp}$ \\
\hline $\begin{array}{l}\text { Myogenin } \\
\text { (mouse) }\end{array}$ & $\begin{array}{l}\text { Forward } \\
\text { Reverse }\end{array}$ & $\begin{array}{l}\text { 5'- GGCATGCAAGGTGTGTAAGA -3' } \\
\text { 5'- ACGATGGACGTAAGGGAGTG -3' }\end{array}$ & 60 & $411 \mathrm{bp}$ \\
\hline $\begin{array}{l}\text { Fast MHC } \\
\text { (mouse) }\end{array}$ & $\begin{array}{l}\text { Forward } \\
\text { Reverse }\end{array}$ & $\begin{array}{l}\text { 5'- CATCGTCCAGGAAGCCC -3' } \\
\text { 5'- TTCGCTTATGATTTTGGTGTGAACC -3' }\end{array}$ & 51 & 574 bp \\
\hline $\begin{array}{l}\text { Tropomyosin } \\
\text { (mouse) }\end{array}$ & $\begin{array}{l}\text { Forward } \\
\text { Reverse }\end{array}$ & $\begin{array}{l}\text { 5'-TGAGTTTGCAGAGAGATCAGTAACC-3' } \\
\text { 5'-GGGACATCCGGCTTGATGAAGGAGTCTTGGGAGG-3' }\end{array}$ & 53 & 189 bp \\
\hline $\begin{array}{l}\text { Troponin-I } \\
\text { (mouse) }\end{array}$ & $\begin{array}{l}\text { Forward } \\
\text { Reverse }\end{array}$ & $\begin{array}{l}\text { 5'- GAAGGAGAACTACCTGTCAGA -3' } \\
\text { 5'- TGGGCAGTTAGGACTCAGACTC -3' }\end{array}$ & 51 & $437 \mathrm{bp}$ \\
\hline $\begin{array}{l}\text { MyoD } \\
\text { (S. macrurus) }\end{array}$ & $\begin{array}{l}\text { Forward } \\
\text { Reverse }\end{array}$ & $\begin{array}{l}\text { 5'- GCACGTCTACGAATCCTAATCAG -3' } \\
\text { 5'- CAAGGGCTGCCATCAGAG -3' }\end{array}$ & 53 & 394 bp \\
\hline $\begin{array}{l}\text { Myogenin } \\
\text { (S. macrurus) }\end{array}$ & $\begin{array}{l}\text { Forward } \\
\text { Reverse }\end{array}$ & $\begin{array}{l}\text { 5'- CGTACTTTTTCCCTGACCAGC -3' } \\
\text { 5'- ATGTTAGCATGTTCGGAGGAGTC -3' }\end{array}$ & 55 & 658 bp \\
\hline
\end{tabular}

transfected cells (Fig. 3B). Bands corresponding to endogenous tropomyosin and troponin-I were also detected in 10T1/2 cells transfected with both murine and $S$. macrurus MRFs (Fig. 3B), although at apparently lower intensities than those of $\mathrm{MHC}$ mRNAs. These data demonstrate the induction of multiple differentiation muscle markers by murine and teleost MRFs in this nonmuscle cell line.

The myogenic induction potential of $\mathcal{S}$. macrurus MRFs on mammalian non-muscle cells was also tested on embryonic fibroblasts (NIH3T3 cell line). Fig. 3C shows a representative image of NIH3T3 fibroblasts that were transfected with $S$. macrurus MRF cDNA and subsequently immunolabeled with the anti-MHC antibody MF20 three days after transfection. Both SmMyoD and SmMyoG cDNAs induced some NIH3T3 cells to express MHC and fuse to give rise to multinucleated cells. Detection of $\mathrm{MHC}$ staining in NIH3T3 cells was not restricted to multinucleated cells after transfection with either murine or $\mathcal{S}$. macrurus MRFs, as mononucleated cells were also immunolabeled by the anti-MHC antibody similarly to $10 \mathrm{~T} 1 / 2$ cells. These data demonstrate that SmMyoD and SmMyoG can function in a heterologous system to induce the myogenic phenotype on different mammalian nonmuscle cell lines (i.e., 10T1/2 cells, Fig. 3A; NIH3T3 cells, Fig. $3 \mathrm{C})$, and are consistent with an MRF-dependent transcriptional program of myogenesis that is functionally conserved in $\mathcal{S}$. macrurus.

\section{Induction of mammalian MRFs by S. macrurus MyoD and myogenin}

In vitro studies have shown that MyoD and myogenin can regulate their own expression via a positive feedback mechanism of transcriptional activation (Braun et al., 1989; Weintraub et al., 1989; Tapscott, 2005). In addition, endogenous MyoD and myogenin can be activated by exogenously expressed MRFs during skeletal differentiation in 10T1/2 cells (Auradé et al., 1994). To test whether $\mathcal{S}$. macrurus MRFs can also induce the expression of endogenous MRFs, we assayed for the expression of mouse MyoD and myogenin mRNAs and proteins in 10T1/2 cells 2 days after transfection with each $\mathcal{S}$. macrurus MRF. RT-PCR analysis showed that transfection with either SmMyoD and SmMyoG resulted in the transcription of endogenous MyoD and myogenin (Fig. 4A). Western blots and immunofluorescence studies revealed that induction of the endogenous myogenin by each $\mathcal{S}$. macrurus MRF and by mouse MyoD was also detected at the protein level (Fig. 4B and $4 \mathrm{C}$ ).

Auto- and cross-regulation of MRFs have been shown to be cell line dependent. Unlike in 10T1/2 cells, forced expression of MyoD in NIH3T3 cells does not induce endogenous MyoD. NIH3T3 cells do respond to exogenous MyoD and myogenin by expressing myogenin and MyoD, respectively (Thayer et al., 1989; Russo etal., 1998). In the present study, we detected MyoD and myogenin transcripts in NIH3T3 cells transfected with both mouse MRFs (Fig. 4D). Detection of MyoD mRNA in NIH3T3 cells transfected with mouse MyoD (mMyoD in Fig. 4D) does not necessarily contradict published observations that exogenous MyoD does not induce its own expression in this cell line. Since our experimental approach could not differentiate between exogenous and endogenous MRFs, MRF transcripts detected 2 days after transfection with mMyoD and mMyoG, respectively, could likely reflect the levels of exogenous MRFs in the cells. However, 
A
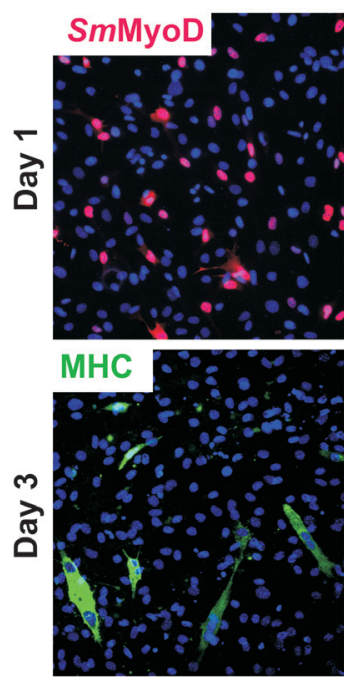

Transfected 10T1/2 Cells
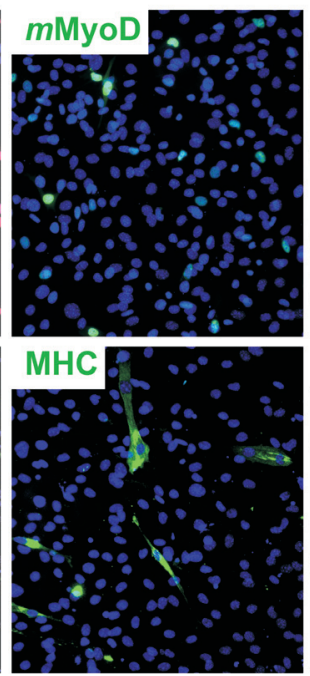
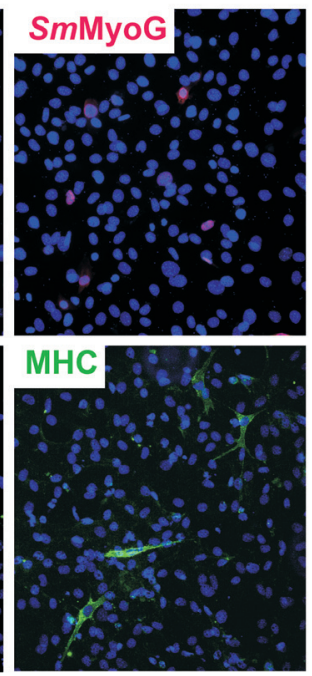
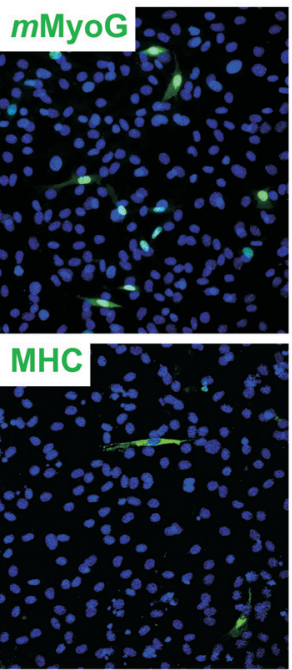

B

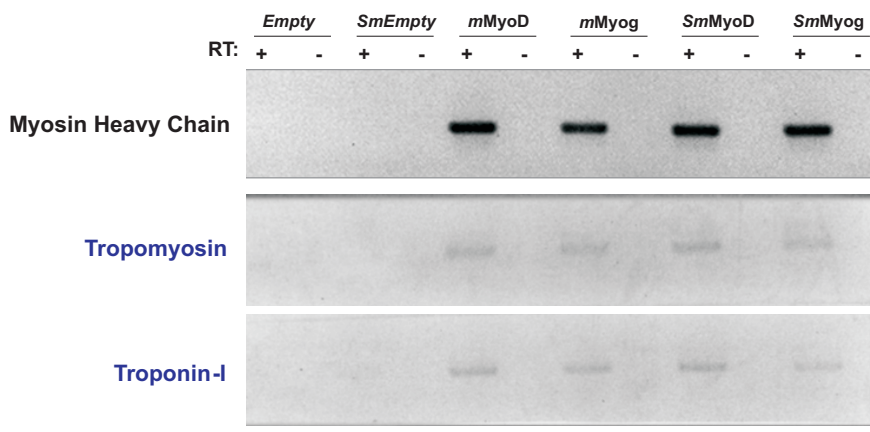

C
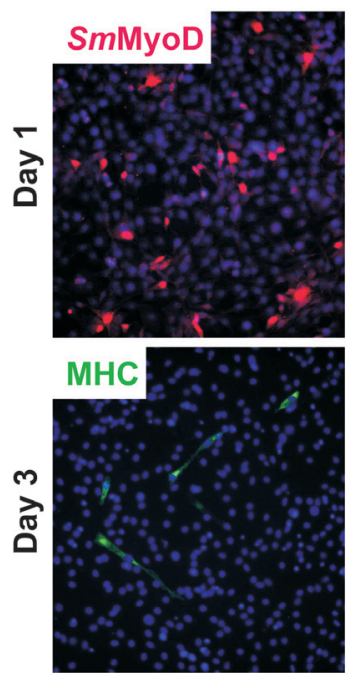

Transfected NIH3T3 Cells
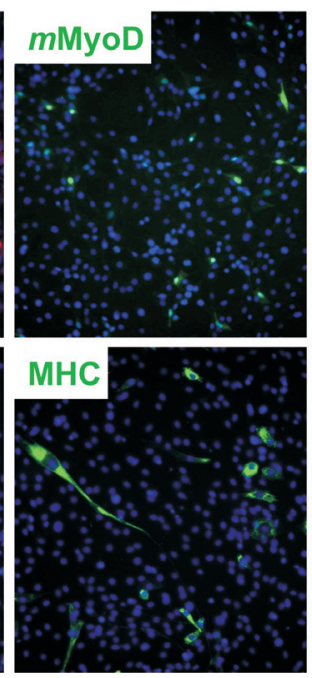
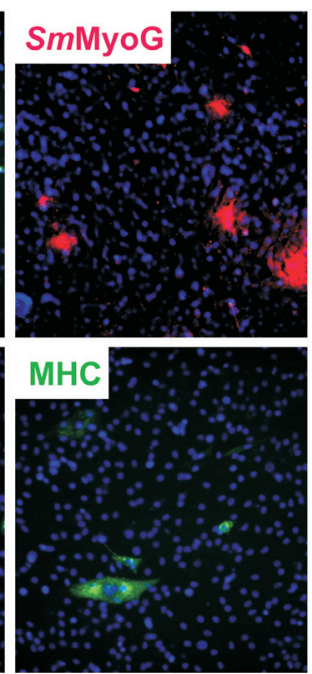
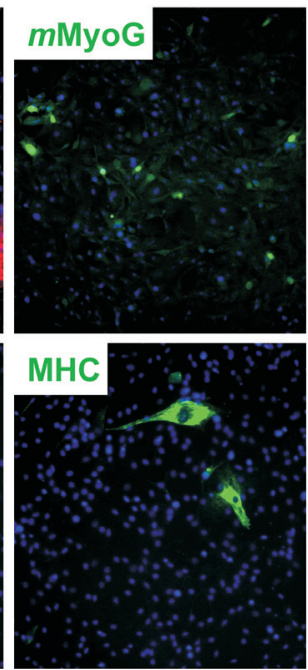

the detection of myogenin after mMyoD transfection and MyoD after mMyoG transfection is interpreted to indicate a clear cross-regulation between these mammalian MRFs. Only SmMyoD was found to induce endogenous myogenin (Fig. 4D). Together, these results demonstrate that both SmMyoD and SmMyoG are similar in function to their mammalian counterparts by demonstrating their capability of transcriptional activation of endogenous MRF genes in 10T1/2, but not completely in NIH3T3 cells.

\section{Discussion}

Previous studies on the transcriptional regulation of the muscle program in electrocytes of $\mathcal{S}$. macrurus revealed that all four MRFs are expressed in mature electrocytes despite the fact that these cells do not maintain a normal muscle phenotype (Kim etal., 2004; 2008). Moreover, with the exception of MyoD, the endogenous levels of myogenin, Myf5, and MRF4 transcripts in electrocytes were greater than those detected in muscle fibers (Kim et al., 2008). Although previous analyses did not allow us to draw firm conclusions about MRF protein activity in muscle and EO, the present study demonstrates that $\mathcal{S}$. macrurus MRFs can induce the myogenic program in mammalian non-muscle cells. Our conclusion that SmMyoD and SmMyoG act as molecular switches for the myogenic

Fig. 3. Myogenic conversion potential of $\boldsymbol{S}$. macrurus MyoD and myogenin. (A) 10T1/2 cells were transiently transfected with SmMyoD, SmMyoG, mouse MyoD (mMyoD) or mouse myogenin ( $\mathrm{m} M y o g$ ) expressing vectors and assayed for expression of exogenous MRFs (top row) and sarcomeric myosin heavy chain (MHC; bottom row below corresponding MRFs) using immunofluorescence staining with antibodies specific to each protein at day 1 and day 3, respectively. AlexaFluor-546 (red) or AlexaFluor-488 (green) conjugated secondary antibodies were used. (B) 10T1/2 cells were transfected with mouse MyoD (mMyoD), mouse myogenin (mMyog), S. macrurus MyoD (SmMyoD), or myogenin (SmMyoG) and total RNA isolated from cells 3 days after transfection. Total RNA then was processed for RT-PCR as described in Materials and Methods by using the primers specific for mouse fast-MHC, tropomyosin, and troponin-I cDNAs indicated in Table 1. PCR products were resolved on $1 \%$ agarose gel and stained with ethidium bromide. The negative image of the gel is shown. Data shown is representative of results obtained from three different experiments. RT: reverse transcriptase. (C) NIH3T3 cells were transiently transfected with the same expression vectors as used for 10T1/2 cells and assayed for expression of each MRF and MHC as indicated in the figure. Nuclei were counter-stained with Hoechst 33342 (blue). Images were taken at 100x magnification by fluorescence microscopy (Zeiss Axiovert 200M). 
A

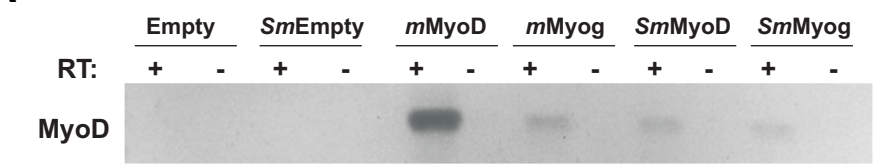

myogenin

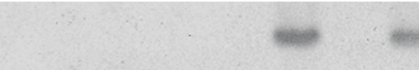

B

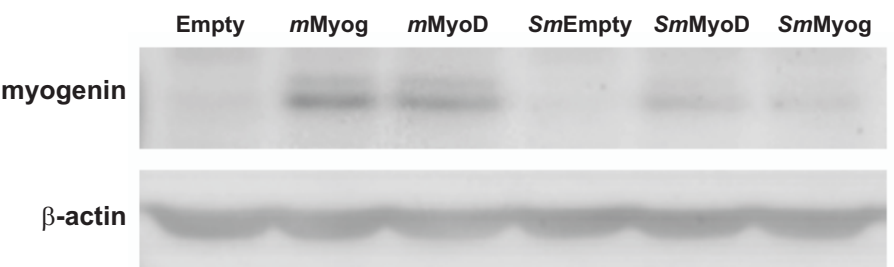

C
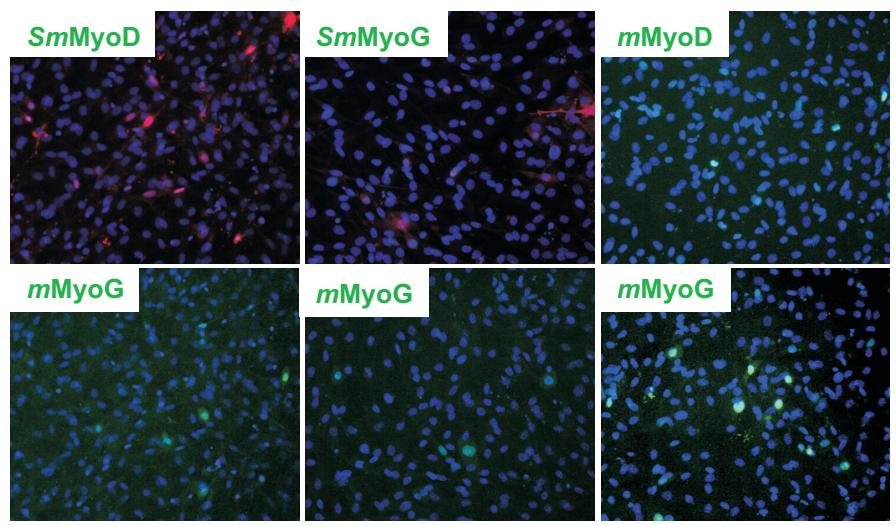

D

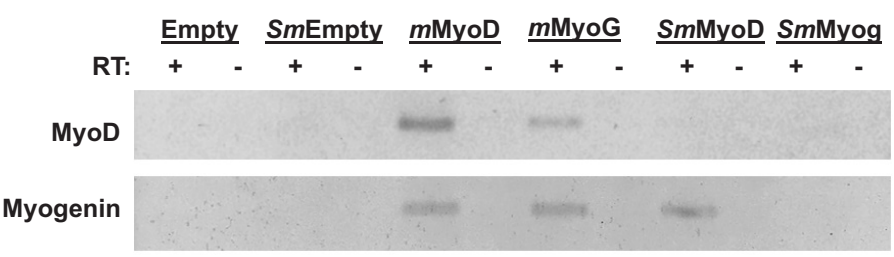

Fig. 4. Auto- and cross-regulation of MRFs by $S$. macrurus MRFs. Mouse 10T1/2 cells or NIH3T3 cells were transfected with $S$. macrurus MRF (SmEmpty, SmMyoD and SmMyoG) and mouse MRFs (Empty, $\mathrm{mMyoD}$ and $\mathrm{mMyog}$ ) and assayed for expression of mouse MyoD or myogenin 2 days after transfection. (A) Detection of transcripts of mouse MyoD and myogenin in 10T1/2 cells by RT-PCR. PCR products were resolved on $1 \%$ agarose gels and stained with ethidium bromide (negative images shown). (B) Detection of mouse myogenin protein in 10T1/2 cells by Western blot analysis using monoclonal anti-myogenin antibody. $\beta$-actin was used as equal loading control. (C) Detection of endogenous myogenin (mMyoG) protein in 10T1/2 cells by immunofluorescence staining (bottom row) was assessed following transient transfection with S. macrurus MyoD (SmMyoD) and myogenin (SmMyoG) and mouse MyoD (mMyoD). Expression of exogenous MRFs was detected with respective antibodies indicated in the figure (top row). Hoechst 33342 was used to stain nuclei (blue) (D) Mouse NIH3T3 cells were transfected with the expression plasmids as described above and assayed for mouse MyoD and myogenin transcript by RT-PCR. program is based on their conversion of non-muscle cells into multinucleated cells that express endogenous MRFs and muscle differentiation markers. To our knowledge, the present data represent the most complete test of the functional conservation of vertebrate non-mammalian MRFs using two murine non-muscle cell lines. Our cell conversion assays at the transcript and protein levels of MRF auto- and cross-regulation and induction of different terminal myogenic markers provide compelling evidence in support of an MRF-dependent transcriptional program of myogenesis in $\mathcal{S}$. macrurus. This is also the first report on the expression pattern of MyoD and myogenin in mature skeletal muscle fibers and electrocytes of $\mathcal{S}$. macrurus using speciesspecific antibodies against these MRFs.

\section{S. macrurus MRFs can substitute for mammalian MyoD and myogenin to induce the myogenic program in non-mamma- lian cells}

Our immunofluorescence assays showed the presence of MHC expression in 10T1/2 cells and NIH3T3 cells after SmMyoD or SmMyoG transfections. MHC expression was not exclusive to multinucleated myotubes as $\mathrm{MHC}$ label was also detected in mononucleated cells, an observation consistent with previous studies using mammalian MRFs (Weintraub, 1989). These data revealed that sarcomeric $\mathrm{MHC}$ expression might be independent of cell fusion in culture conditions. Although SmMyoG also induced 10T1/2 and NIH3T3 cells to adopt a myogenic phenotype, it did so with an apparent lower frequency of conversion than SmMyoD. However, our data also show that the frequency of conversion by mouse myogenin was lower than that by mouse MyoD (compare Fig. 3A and $3 C$ ).

We should note that in the present study comparisons between the ability of MRFs to induce muscle differentiation were not correlated to the transfection efficiency for each MRF overexpression experiment. Cell counts of MHC-positive cells in our preliminary experiments did not yield conclusive relationships between the transfection levels by either murine or $\mathcal{S}$. macrurus MRFs and the levels of myogenic cell conversion observed. Given that the MRF cDNAs are not integrated with a transient transfection approach, and there is a high variability in the number of MRF molecules expressed per cell so as to not allow an accurate assessment of cell conversion, the muscle gene detection assays performed in the present study, i.e., RT-PCR, Western blots, and immunolabeling profiles, were deemed more appropriate in our assessment of the functional conservation of $\mathcal{S}$. macrurus MRFs.

The phenotypic conversion of mammalian non-muscle cells by a non-mammalian MRF is not unique to SmMyoD or SmMyoG. Transfection of 10T1/2 cells with the MyoD homolog from the sea urchin (Venuti et al., 1991) and the nematode C. elegans also converts $10 T 1 / 2$ cells into multinucleated cells that express sarcomeric proteins (Venuti et al., 1991; Krause, 1992; Zhang et al., 1999). We are not aware of similar expression studies that have thoroughly tested the functional conservation of non-mammalian vertebrate MRFs.

\section{Regulation of endogenous MRFs by S. macrurus MyoD and myogenin}

The presence of mouse MyoD and myogenin transcripts in $10 T 1 / 2$ cells transfected with SmMyoD or SmMyoG infers that $S$. macrurus MRFs can functionally bind to the promoters of their 
endogenous mammalian counterparts. Given that methylation of the MyoD promoter renders it to be transcriptionally repressed in 10T1/2 cells, (Jones et al., 1990), forced expression of $\mathcal{S}$. macrurus MRFs almost certainly brings about a reduction of this inhibition. To date, it is not clear how exogenous MyoD can activate the endogenous MyoD promoter in 10T1/2 cells. Moreover, autoregulation by exogenous $\mathcal{S}$. macrurus MRFs is cell-line specific (e.g., 10T1/2 vs NIH3T3, Fig. 4). For example, exogenous MyoD converts NIH3T3 cells to a myogenic phenotype in the absence of induction of the endogenous MyoD (Thayer et al., 1989; Russo et al., 1998). Consistent with the literature, SmMyoD induced the expression of $\mathrm{MHC}$ in the absence of endogenous MyoD in NIH3T3 cells. In contrast, we could not detect endogenous MRFs in SmMyoG transfected NIH3T3 cells despite their expression of $\mathrm{MHC}$ - a finding unlike that obtained with murine MyoG (Fig. 4D). Nonetheless, these results demonstrate that both SmMyoD and SmMyoG are similar in function to the mammalian counterpart by demonstrating their capability of transcriptional activation of endogenous MRF genes in 10T1/2, but not completely in NIH3T3 cells.

Our analysis of the muscle program activation by $\mathcal{S}$. macrurus MRFs does not substantiate any conclusions about the mechanisms by which they influence 10T1/2 and NIH3T3 to differentiate into muscle cells. For instance, we do not know whether SmMyoD directly activates the expression of $\mathrm{MHC}$, tropomyosin, or troponin-I genes by binding to their promoters, or indirectly through the induction of endogenous MyoD or myogenin. Inclusion of highly conserved functional domains in SmMyoD and SmMyoG (Kim et al., 2004) together with an efficiency of muscle gene activation similar to that observed with mouse homologs (present study), intimate that $\mathcal{S}$. macrurus and mammalian MRFs are involved in similar mechanisms of MRF-dependent myogenesis. Studies designed to characterize the transcriptional activity of SmMyoD and SmMyoG conferred through homodimerization or heterodimerization with mammalian MRFs or E-proteins, respectively, will be necessary to more thoroughly evaluate their functional conservation.

\section{Implications on the partial muscle phenotype of electrocytes in S. macrurus}

The presence of some cytoskeletal, sarcomeric and cell signaling proteins in mature electrocytes, such as desmin, $\alpha$-actin, dystrophin, titin, and acetylcholine receptors reflects their differentiation from the myogenic lineage (Kim et al., 2004; Cuellar et al., 2006). Because MRFs are essential for the transcriptional activation of these muscle genes in mammals ( $\mathrm{Li}$ and Capetanaki, 1993; Marsh et al., 1998; Simon and Burden, 1993; Shield et al., 1996; Lin et al., 1991; Gramolini and Jasmin, 1999; Wheeler et al., 1999; Angus et al., 2001), evaluation of the functional conservation of $S$. macrurus MRFs is warranted to determine whether a unique transcriptional mechanism of muscle gene regulation is present in electrocytes. Our present data demonstrate that SmMyoD and SmMyoG are capable of programming muscle differentiation in non-muscle cells similarly to their mammalian counterparts by inducing the expression of known MRF targets $\mathrm{MHC}$, troponin-T, tropomyosin, and troponin-I (Wheeler et al., 1999; Hirao et al., 2004; Toutant et al., 1993; Banerjee-Basu and Buonanno, 1993). Interestingly, previous expression analyses revealed that mature electrocytes transcribe $\mathrm{MHC}$, tropomyosin, and troponin genes but the corresponding protein products could not be detected (Cuellar et al., 2006, unpublished data). Further studies of the differential expression of select muscle genes in electrocytes are likely to provide insight into the possible roles that additional transcriptional and post-transcriptional mechanisms might play in the homeostasis of muscle-specific properties of the EO after differentiation.

\section{Materials and Methods}

\section{Sub-cloning of full length cDNA sequences of S. macrurus MyoD and myogenin}

Full-length coding cDNA sequences of $S$. macrurus MyoD and myogenin (Kim et al., 2004; GenBAnk accession sequences AY396566 and AY396565, respectively) were first cloned into the pDrive vector (Qiagen, Valencia, CA), and subsequently subcloned into the pET15b vector (Novagen, San Diego, CA). For subcloning, primers were designed following the BD In-Fusion ${ }^{\mathrm{TM}}$ Dry-Down PCR cloning Kit user manual (BD Bioscience, San Jose, CA). Briefly, the 5'-end of both forward and reverse primers ( sense MyoD: 5'-CCG CTC GAG ATG GAA CTG TCC GAT ATC CC-3', anti-sense MyoD: 5'-CGG GAT CCT TAC AGA ACC TGG TAG ATC GGA T-3', sense myogenin: 5'-CCG CTC GAG ATG GAA CTC TTC GAG ACT AA -3', anti-sense myogenin: 5'-CGG GAT CCT TAT TTA ATA TCC ACG GAG TAG G-3') shared 15 bases of sequence homology with the sequences on either side of the point of insertion and one extra base that included an Xhol and BamHI site, which flanked the gene-specific sequence of MyoD or myogenin. PCR was performed with HiFi Taq DNA polymerase (Invitrogen, Carlsbad, CA) for 25 cycles, and the fragments were purified using the Qiaquick PCR Purification Kit (Qiagen). The pET15b vector was digested with Xhol and BamHI restriction enzymes and gel-purified using the Qiaquick Gel Extraction Kit (Qiagen). Recombination between the pET15b and each PCR product was carried out using the BD In-Fusion ${ }^{\mathrm{TM}}$ Cloning Procedure in the BD In-Fusion ${ }^{\mathrm{TM}}$ Dry-Down PCR Cloning Kit per the manufacturer's instructions. Bacterial colonies were screened for plasmids with the MyoD or myogenin gene insertion by colony PCR, and confirmed by DNA sequencing using the ABI 3130xI Genetic Analyzer.

\section{Protein purification and antibody production}

MyoD and myogenin plasmids were expressed in Escherichia coli BL21 (DE3) as N-terminal hexahistidine-tagged fusion protein using Studier's auto-induction procedure (Studier, 2005) and purified from the insoluble fraction as described previously (Jonsson et al., 1993). Briefly, cells were grown in $500 \mathrm{ml}$ of ZYM-5052 and supplemented with $50 \mu \mathrm{g} /$ $\mathrm{ml}$ ampicillin following the auto-induction procedure (Studier, 2005). Cells were then centrifuged, resuspended in $40 \mathrm{ml}$ Buffer $\mathrm{A}$ ( $20 \mathrm{mM}$ Tris pH 8.0, $6 \mathrm{M}$ guanidine $\mathrm{HCl}, 1 \mathrm{M} \mathrm{NaCl}, 0.1 \mathrm{mM}$ EDTA and $1 \mathrm{mM} \mathrm{DTT}$ ), shaken at room temperature (RT) for $1 \mathrm{hr}$ at 150 RPMS, and centrifuged for $30 \mathrm{~min}$ at $30,000 \times \mathrm{g}$ to harvest the supernatant. The material was purified through a $1 \mathrm{ml}$ nickel agarose resin (Qiagen) equilibrated with 1X Buffer A and total protein was eluted with a stepwise decrease in $\mathrm{pH}(6.3,5.9$ and 4.5). Fractions containing protein were dialyzed and refolded in $3 \mathrm{M}$ urea/ Buffer B (40 mM HEPES pH 7.4, $1 \mathrm{M} \mathrm{NaCl}, 10 \mathrm{mM} \beta$-mercaptoethanol, $0.4 \%$ NP40, $10 \%$ glycerol) and the urea concentration dropped by $1 \mathrm{M}$. A final dialysis was made in Buffer C (40 mM HEPES pH 7.4, $0.2 \mathrm{M} \mathrm{NaCl}$, $1 \mathrm{mM}$ DTT, $0.4 \%$ NP40, 10\% glycerol). Total protein concentration was measured by the Bradford method (BioRad, Hercules, CA) and stored in aliquots at $-80^{\circ} \mathrm{C}$.

\section{MyoD and myogenin polyclonal antibody generation and Western blot analyses}

Rabbits were immunized with the purified proteins for antibody production (Cell Essentials, Inc. Boston, MA). After initial immunization, rabbits were boosted twice, and test bleeds were performed. After the final boost, rabbits were bled and sera from production bleeds were used 
in the experiments in this study. For immunoblot analysis, purified MyoD $(10 \mu \mathrm{l} ; 0.3 \mu \mathrm{g} / \mu \mathrm{l})$ and myogenin $(10 \mu \mathrm{l} ; 0.7 \mu \mathrm{g} / \mu \mathrm{l})$ proteins were electrophoresed on $4-12 \%$ Bis-Tris SDS-polyacrylamide gel electrophoresis (PAGE) gels with running buffer (Invitrogen, Carlsbad, CA). Proteins were transferred to nitrocellulose membranes (Biorad, Hercules, CA) according to the manufacturer's recommendations. Membranes were incubated in blocking buffer ( $5 \%$ nonfat dried milk in TBS-Tween: $50 \mathrm{mM}$ Tris, $\mathrm{pH}$ 7.6, $150 \mathrm{mM} \mathrm{NaCl}$ ) for $1 \mathrm{hr}$ at RT. Antibodies were diluted 1:2000 in blocking buffer and incubated with the membrane for $1 \mathrm{hr}$ at RT. Goat antirabbit $\lg G(\mathrm{Fc})$ alkaline phosphatase-conjugated (Promega, Madison, $\mathrm{WI}$ ) was diluted 1:2,000 in blocking buffer and incubated with the membrane for $1 \mathrm{hr}$ at RT. Antibody label was detected by phosphatase activity with NBT/BCIP (Sigma, St. Louis, MI) as per manufacturer's instructions.

\section{Cell culture and transfection with mouse and S. macrurus MRFs}

The $\mathrm{C} 3 \mathrm{H} / 10 \mathrm{~T} 1 / 2$ (referred to as 10T1/2 hereafter) mouse embryonic stem cell line was purchased from American Type Cell Culture (Manassas, VA) and maintained in growth medium [Basal Medium Eagle (BME) supplemented with $10 \%$ FBS and $2 \mathrm{mM}$ L-glutamine]. NIH3T3 mouse embryonic fibroblasts were generously provided by Dr. Stephen Tapscott (Fred Hutchinson Cancer Research Center, Seattle, WA) and maintained in growth medium consisting of Dulbecco's Modified Eagle Medium (DMEM) supplemented with $10 \%$ bovine calf serum and 100 units $/ \mathrm{ml}$ penicillin $\mathrm{G}$ and $100 \mu \mathrm{g} / \mathrm{ml}$ streptomycin. Cells were transfected with plasmids expressing mouse MyoD or myogenin (cloned into pEMSVscribe 2 ; a gift from Dr. Konieczny, Purdue University, West Lafayette, IN) or $S$. macrurus MyoD or myogenin (cloned into pcDNA4T/ $\mathrm{O}$, Invitrogen) to test for myogenic conversion. pEMSVscribe $\alpha 2$ and pcDNA4T/O vectors without insert were used as controls for mouse and $S$. macrurus MRFs, respectively. Transfections were carried out using Fugene-6 (Roche, Indianapolis, IN) on 10T1/2 cells and lipofectamine (Invitrogen) on NIH3T3 cells following manufacturer's instructions. Transfection efficiency was determined after $24 \mathrm{hrs}$ by MRF-positive nuclei to total cell number in 7 randomly selected microscopic fields per dish. Cells were switched to differentiation medium (DMEM supplemented with $2 \%$ horse serum) $24 \mathrm{hrs}$ after transfection, and further incubated up to 2 days with daily medium change. Cell culture reagents (culture media, serum, antibiotics etc) were purchased from Invitrogen (Carlsbad, CA) unless otherwise indicated.

\section{Reverse transcription-polymerase chain reaction (RT-PCR)}

Total cellular RNA was isolated from each population of transfected cells at different time points using the Qiagen RNeasy Mini kit per the manufacturer's protocol. Residual DNA was removed by treatment with DNase I, Amplification Grade (Invitrogen), and total RNA concentrations were determined by spectrophotometry $\left(A_{260} / A_{280}\right)$. cDNAs were synthesized from $0.50 \mu \mathrm{g}$ total RNA using the Superscript First-Strand Synthesis System for RT-PCR (Invitrogen). To monitor DNA contamination in all experiments, control reactions were performed without reverse transcriptase. Gene-specific homologous primers for mouse MyoD and myogenin, mouse fast myosin heavy chain (MHC) isoforms, and $S$. macrurus MyoD and myogenin, mouse tropomyosin and troponin-I (Table 1) were used to characterize the transcription profile of these cells. PCR amplification of the cDNAs $(\sim 1 \mu \mathrm{g})$ was performed using either Platinum Taq polymerase (Invitrogen) or Paq polymerase (Stratagene, La Jolla, CA). For amplification of mouse MHC and MRF cDNAs, 27-35 cycles were performed with denaturation at $94^{\circ} \mathrm{C}$ for 30 seconds, primerannealing at $51-60^{\circ} \mathrm{C}$ (Table 1) for 30 seconds, and elongation at $72^{\circ} \mathrm{C}$ for 30 seconds following an initial denaturation at $94^{\circ} \mathrm{C}$ for 2 min. For amplification of mouse tropomyosin and troponin-I cDNAs, 35 cycles were performed with denaturation at $95^{\circ} \mathrm{C}$ for 20 seconds, primerannealing at $51-53^{\circ} \mathrm{C}$ (Table 1) for 20 seconds, and elongation at $72^{\circ} \mathrm{C}$ for 30 seconds following an initial denaturation at $95^{\circ} \mathrm{C}$ for 2 minutes. In all PCR reactions, a final elongation step was performed for $5 \mathrm{~min}$ at $72^{\circ} \mathrm{C}$. Amplification was maximized by optimizing annealing temperature for each PCR primer pair. PCR products were electrophoresed on $1 \%$ agarose gels stained with ethidium bromide to verify product size. Amplicons were purified using Qiagen's QIAquick PCR Purification kit and their nucleotide sequences were verified by Elim Biopharmaceuticals (Hayward, CA). Sequence information was downloaded to align forward and reverse sequences in order to find the consensus sequence using VectorNTI software from Invitrogen. Consensus sequences were then entered into the NCBI database to identify mammalian homologs.

\section{Immunofluorescence: cultured cells and tissue sections}

Cultured cells transfected with MRF-expressing plasmids were fixed in cold methanol for $15 \mathrm{~min}$ at $-20^{\circ} \mathrm{C}$ and processed for staining. Briefly, cells were washed with phosphate buffered saline (PBS), permeabilized in PBS containing $0.1 \%$ Trition $\mathrm{X}-100$ (PBS-T) for $5 \mathrm{~min}$ and blocked in blocking buffer ( $3 \%$ bovine serum albumin in PBS-T). Cells were then incubated with primary antibody diluted in blocking buffer containing Hoechst 33342 for $1 \mathrm{hr}$ at $37^{\circ} \mathrm{C}$. Antibodies used were: monoclonal mouse anti-MyoD (1:100, BD Pharmingen), monoclonal mouse anti-myogenin (F5D, 1:5, Hybridoma Bank), monoclonal mouse anti-MHC (MF20, 1:5, Hybridoma Bank), polyclonal S. macrurus MyoD (1:20, Cell Essentials, Boston, MA), and polyclonal $\mathcal{S}$. macrurus myogenin (1:20, Cell Essentials). Antibody-antigen complexes were visualized using AlexaFluor-488 or AlexaFluor-546 secondary antibodies (anti-mouse or anti-rabbit, 1:200; Molecular Probes, Eugene, OR). Images of immunolabeled cells were captured on a Zeiss Axiovert 200M microscope equipped with Axiovision software version 4.5 and interfaced with a CCD fluorescent camera (AxioCam MRm, Carl Zeiss, Thornwood, NY).

Serial transverse and longitudinal cryosections (20-30 $\mu \mathrm{m}$ thick) of control adult tails were mounted on Superfrost Plus glass slides (Fisher, Pittsburgh, PA) and air-dried at RT. Sections were fixed by immersion in $4 \%$ buffered paraformaldehyde $\left(\mathrm{pH} 7.4,20 \mathrm{~min}, 37^{\circ} \mathrm{C}\right)$ and rinsed twice in $0.1 \mathrm{M}$ PBS ( $\mathrm{pH} 7.4$ ). Slides were immersed in permeabilization solution (0.5\% Triton X-100 in PBS) for $30 \mathrm{~min}$ and subsequently incubated in $1 \%$ blocking reagent (TSA kit, Invitrogen) for $1 \mathrm{hr}$ at RT. Rabbit polyclonal antibodies against $\mathcal{S}$. macrurus-specific MyoD (1:20) and myogenin $(1: 20)$ (Cell Essentials) were diluted in 1\% blocking solution and applied to separate slides for 15-20 hr at RT. Tissue sections were incubated in $1 \%$ blocking solution without primary antibodies to assess non-specific labeling by secondary antibodies. Sections were rinsed in PBS and incubated in horseradish peroxidase-conjugated goat anti-rabbit $\lg G$ (TSA kit, diluted $1: 100$ in $1 \%$ blocking solution) for $1 \mathrm{hr}$. Tissue sections were rinsed in PBS, and incubated in AlexaFluor-488 tyramide working solution (TSA kit, 10 min., diluted $1: 1000$ in $0.0015 \% \mathrm{H}_{2} \mathrm{O}_{2}$ ). Sections were rinsed in PBS, counterstained with Hoechst 33342, rinsed in water and cover-slipped with Gelmount (Biomeda, Foster City, CA).

\section{SDS-PAGE and Western blot analysis of cultured cell lysates and tissue homogenates}

Total cell lysates from MRF-transfected cells were prepared using lysis buffer [20mM Tris- $\mathrm{HCl}$ pH 7.5, $150 \mathrm{mM} \mathrm{NaCl}, 1 \mathrm{mM} \mathrm{Na}{ }_{2}$ EDTA, $1 \mathrm{mM}$ EGTA, $1 \%$ Triton, $2.5 \mathrm{mM}$ sodium pyrophosphate, $1 \mathrm{mM} \beta$-glycerophosphate, $1 \mathrm{mM} \mathrm{Na}_{3} \mathrm{VO}_{4}, 1 \mu \mathrm{g} / \mathrm{ml}$ leupeptin and $1 \mathrm{mM}$ PMSF and protease inhibitor cocktail (Roche, Indianapolis, IN)] on ice for $5 \mathrm{~min}$. The cell lysates were scraped off and homogenized with a 21-gauge needle. Lysates were then centrifuged at $13,000 \times \mathrm{g}$ for $15 \mathrm{~min}$ at $4^{\circ} \mathrm{C}$, and supernatants were collected. Protein concentration was measured using the Bradford assay (Biorad, Hercules, CA). Total proteins $(50 \mu \mathrm{g}$ per sample) were separated by SDS-PAGE (4-15\%), and transferred onto PVDF membranes. Membranes were washed with TBS-T $(0.1 \%$ Tween20 in Tris buffered saline) and incubated in blocking buffer ( $3 \%$ non-fat dry milk in TBS-T) for 60 min at RT. Membranes were then incubated with primary antibody diluted in $5 \%$ BSA in TBS-T at $4{ }^{\circ} \mathrm{C}$ overnight. Primary antibodies used were the same as those used for immunofluorescence staining (see above). Membranes were washed with PBS-T and incubated with anti-mouse or anti-rabbit HRP-conjugated secondary antibod- 
ies (1:5000 dilution, BioRad) for $1 \mathrm{hr}$ at RT. Colorimetric analysis was used to visualize the specific protein bands using the Opti- $4 \mathrm{CN}$ substrate (BioRad).

Similar procedures were followed for the immunoblot analysis of protein homogenates from skeletal muscle and electric organ with antibodies against $\mathrm{S}$. macrurus-specific MyoD and myogenin proteins, except that total protein was isolated from skeletal muscle and electric organ following the protocol of Talmadge et al.,1993). All subsequent steps including: measurements of protein concentration, protein separation through gel electrophoresis, protein transfer onto PVDF membranes, and immunoblotting with anti-MyoD $(1: 1,00)$ and anti-Myogenin $(1: 1,000)$ antibodies, were as described above for Western blots with cell lysates.

\section{Acknowledgements}

This research was supported by National Institute of Health Grants S06-GM08136-27, RR16480-01, and U56-CA96286 (G.A.U.). We are grateful to Stephen Konieczny for mouse MyoD and myogenin clones; Tan Wang and Xialin Xu for purification of S. macrurus MyoD and myogenin proteins; Jung $A$. Kim and two anonymous reviewers for providing criticalsuggestions in earliermanuscript drafts, and the Cell and Organismal Culture Facility at NMSU for its culture services.

\section{References}

ANGUS, L.M., CHAN, R.Y.Y. and JASMIN B.J. (2001). Role of intronic E and N-box motifs in the transcriptional induction of the acetylcholinesterase gene during myogenic differentiation. J. Biol. Chem. 276: 17603-17609.

ATCHLEY, W.R., FITCH, W.M. and BRONNER-FRASER, M. (1994). Molecular evolution of the MyoD family of transcription factors. Proc. Natl. Acad. Sci. USA 91: $11522-11526$

AURADÉ, F., PINSET, C., CHAFEY, P., GROS, F. and MONTARRAS, D. (1994). Myf5, MyoD, myogenin and MRF4 myogenic derivatives of the embryonic mesenchymal cell line $\mathrm{C} 3 \mathrm{H} 10 \mathrm{~T} 1 / 2$ exhibit the same adult muscle phenotype. Differentiation. 55: 185-192.

BANERJEE-BASU, S. and BUONANNO, A. (1993). Cis-acting sequences of the rat troponin I slow gene confer tissue- and development-specific transcription in cultured muscle cells as well as fiber type specificity in transgenic mice. $\mathrm{Mo} / \mathrm{Ce} / \mathrm{l}$ Biol. 13 11:7019-28.

BENNETT, M.V. (1970). Comparative physiology: electric organs. Annu. Rev. Physiol. 32: 471-528

BRAUN, T., BOBER, E., BUSCHHAUSEN-DENKER, G., KOHTZ, S., GRZESCHIK, K.H. and ARNOLD, H.H. (1989). Differential expression of myogenic determination genes in muscle cells: possible autoactivation by the Myf gene products. EMBO J. 8: 3617-3625.

CHOI, J., COSTA, M.L., MERMELSTEIN, C.S., CHAGAS, C., HOLTZER, S and HOLTZER, H. (1990). MyoD converts primary dermal fibroblasts, chondroblasts, smooth muscle, and retinal pigmented epithelial cells into striated mononucleated myoblasts and multinucleated myotubes. Proc. Natl. Acad. Sci. USA 87: 7988-7992.

CUELLAR, H., KIM, J.A. and UNGUEZ, G.A. (2006). Evidence of post-transcriptional regulation in the maintenance of a partial muscle phenotype by electrogenic cells of $S$. macrurus. FASEB J. 20: 2540.

DELFINI, M.C. and DUPREZ, D. (2004). Ectopic Myf5 or MyoD prevents the neuronal differentiation program in addition to inducing skeletal muscle differentiation, in the chick neural tube. Development. 131: 713-723.

EMERSON, C.P. (1990). Myogenesis and developmental control genes. Curr. Opin. Cell. Biol. 2: 1065-1075.

FUJISAWA-SEHARA, A., NABESHIMA, Y., KOMIYA, T., UETSUKI, T., ASAKURA, A. and NABESHIMA, Y. (1992). Differential trans-activation of muscle-specific regulatory elements including the mysosin light chain box by chicken MyoD, myogenin, and MRF4. J. Biol. Chem. 267: 10031-10038.

GRAMOLINI, A.O. and JASMIN, B.J. (1999). Expression of the utrophin gene during myogenic differentiation. Nuc. Acids Res. 27: 3603-3609.

GROUNDS, M.D., GARRETT, K.L. and BEILHARZ, M.W. (1992). The transcription of MyoD1 and myogenin genes in thymic cells in vivo. Exp. Cell. Res. 198: 357 -
361.

HIRAO, C., YONEMURA, I. and MIYAZAKI, J-C. (2004). Genomic structure of the chicken slow skeletal muscle troponin T gene. Gene. 338: 243-256.

JONES, P.A., WOLKOWICZ, M.J., RIDEOUT, W.M. 3RD, GONZALES, F.A., MARZIASZ, C.M., COETZEE, G.A. and TAPSCOTT, S.J. (1990). De novo methylation of the MyoD1 CpG island during the establishment of immortal cell lines. Proc. Natl. Acad. Sci. USA 87: 6117-6121.

JONSSON, C.B., DONZELLA, G.A. and ROTH, M.J. (1993). Characterization of the forward and reverse integration reactions of the Moloney murine leukemia virus integrase protein purified from Escherichia coli. J. Biol. Chem. 268: 1462-1469.

KIM, J.A., JONSSON, C.B., CALDERONE, T. and UNGUEZ, G.A. (2004). Transcription of MyoD and myogenin in the non-contractile electrogenic cells of the weakly electric fish, Sternopygus macrurus. Dev. Genes Evol. 214: 380-392.

KIM, J.A., LANEY, C., CURRY, J. and UNGUEZ, G.A. (2008). Expression of myogenic regulatory factors in the muscle derived electric organ of Sternopygus macrurus. J Exp Biol. 211: 2172-2184.

KRANER, S.D., RICH, M.M., SHOLL, M.A., ZHOU, H., ZORC, C.S., KALLEN, R.G and BARCHI, R.L. (1999). Interaction between the skeletal muscle type I sodium channel promoter E-box and an upstream repressor element - Release of repression by myogenin. J. Biol. Chem. 274: 8129-8136.

KRAUSE, M., FIRE, A., WHITE-HARRISON, S., WEINTRAUB, H. and TAPSCOTT, S. (1992). Functional conservation of nematode and vertebrate myogenic regulatory factors. J. Cell. Sci. Suppl. 16: 111-115.

LI, H. and CAPETANAKI, Y. (1993). Regulation of the mouse desmin gene: transactivation by MyoD, myogenin, MRF4 and Myf5. Nuc. Acids Res. 21: 335 343.

LIN, H., YUTZEY, K.E. and KONIECZNY, S.F. (1991). Muscle specific expression of the troponin I gene requires interactions between helix-loop-helix muscle regulatory factors and ubiquitous transcription factors. Mol. Cell. Biol. 11: 267 280.

MARSH, D.R., CARSON, J.A., STEWART, L.N. and BOOTH, F.W. (1998). Activation of the skeletal alpha-actin promoter during muscle regeneration. J. Muscle Res. Cell. Motil. 19: 897-907.

MAYER, D.C. and LEINWAND, L.A. (1997). Sarcomeric gene expression and contractility in myofibroblasts. J. Cell. Biol. 139: 1477-1484.

NABESHIMA, Y., HANAOKA, K., HAYASAKA, M., ESUMI, E., LI, S., NONAKA, I. and NABESHIMA, Y. (1993). Myogenin gene disruption results in perinatal lethality because of severe muscle defect. Nature. 364: 532-535.

PATTERSON, J.M. and ZAKON, H.H. (1993). Bromodeoxyuridine labeling reveals a class of satellite-like cells within the electric organ. J. Neurobiol. 24: 660-674.

PATTERSON, J.M. and ZAKON, H.H. (1996). Differential expression of proteins in muscle and electric organ, a muscle derivative. J. Comp. Neurol. 370: 367-376.

RUDNICKI, M.A., SCHNEGELSBERG, P.N., STEAD, R.H., BRAUN, T., ARNOLD, H.H. and JAENISCH, R. (1993). MyoD or Myf-5 is required for the formation of skeletal muscle. Cell. 75: 1351-1359.

Russo, S., TOMATIS, D., COLLO, G., TARONE, G. and TATÒ, F. (1998). Myogenic conversion of NIH3T3 cells by exogenous MyoD family members: dissociation of terminal differentiation from myotube formation. J. Cell. Sci. 111 691-700

SHIELD, M.A., HAUGEN, H.S., CLEGG, C.H. and HAUSCHKA, S.D. (1996). E-box sites and a proximalregulatory region of the muscle creatine kinase gene differentially regulate expression in diverse skeletal muscles and cardiac muscle of transgenic mice. Mol. Cell. Biol. 16: 5058-5068.

SIMON, A.M. and BURDEN, S.J. (1993). An E box mediates activation and repression of the acetylcholine receptor delta-subunit gene during myogenesis. Mol. Cell. Biol. 13: 5133-5140

STUDIER, F.W. (2005). Protein production by auto-induction in high density shaking cultures. Protein Expr. Purif. 41: 207-234

TAKEBAYASHI-SUZUKI, K., PAULIKS, L.B., ELTSEFON, Y. and MIKAWA, T. (2001). Purkinje fibers of the avian heart express a myogenic transcription factor program distinct from cardiac and skeletal muscle. Dev. Biol. 234: 390-401.

TAPSCOTT, S.J. (2005). The circuitry of a master switch: Myod and the regulation of skeletal muscle gene transcription. Development. 132: 2685-2695.

TALMADGE, R.J. AND ROY, R.R. (1993). Electrophoretic separation of rat skeletal muscle myosin heavy chain isoforms. J. Appl. Physiol. 75: 2337-2340. 
THAYER, M.J., TAPSCOTT, S.J., DAVIS, R.L., WRIGHT, W.E., LASSAR, A.B. and WEINTRAUB, H. (1989). Positive autoregulation of the myogenic determination gene MyoD1. Cell. 58: 241-248.

TOUTANT, M., FISZMAN, M.Y., LEMONNIER, M. (1993). The muscle specific promoter of chick beta tropomyosin gene requires helix-loop-helix myogenic regulatory factors and ubiquitous transcription factors. C R Acad Sci III. 316:711-5

UNGUEZ, G.A. and ZAKON, H.H. (1998). Reexpression of myogenic proteins in mature electric organ after removal of neural input. J. Neurosci. 18: 9924-9935.

VENUTI, J.M., GOLDBERG, L., CHAKRABORTY, T., OLSON, E.N. and KLEIN, W.H. (1991). A myogenic factor from sea urchin embryos capable of programming muscle differentiation in mammalian cells. Proc. Natl. Acad. Sci. USA88: 6219-6223.
WEINTRAUB, H., TAPSCOTT, S.J., DAVIS, R.L., THAYER, M.J., ADAM, M.A., LASSAR A.B. and MILLER, A.D. (1989). Activation of muscle-specific genes in pigment, nerve, fat, liver, and fibroblast cell lines by forced expression of MyoD. Proc. Natl. Acad. Sci. USA 86: 5434-5438.

WEINTRAUB, H. (1993). The MyoD family and myogenesis: redundancy, networks, and thresholds. Cell. 75: 1241-1244.

WHEELER, M.T., SNYDER, E.C., PATTERSON, M.N. and SWOAP, S.J. (1999) An E-box within the MHC IIB gene is bound by MyoD and is required for gene expression in fast muscle. Am. J. Physiol. 276: 1069-1078.

ZHANG, J.M., CHEN, L., KRAUSE, M., FIRE, A. and PATERSON, B.M. (1999). Evolutionary conservation of MyoD function and differential utilization of $E$ proteins. Dev. Biol. 208: 465-472.

\section{Further Related Reading, published previously in the Int. J. Dev. Biol.}

See our recent Special Issue Fertilization, in honor of David L. Garbers and edited by Paul M. Wassarman and Victor D. Vacquier at: http://www.ijdb.ehu.es/web/contents.php?vol=52\&issue=5-6

A comparative analysis of Meox1 and Meox 2 in the developing somites and limbs of the chick embryo Susan Reijntjes, Sigmar Stricker and Baljinder S. Mankoo Int. J. Dev. Biol. (2007) 51: 753-759

Myoskeletin, a factor related to Myocardin, is expressed in somites and required for hypaxial muscle formation in Xenopus Hui Zhao, Martha L. Rebbert and Igor B. Dawid

Int. J. Dev. Biol. (2007) 51: 315-320

Xtbx6r, a novel T-box gene expressed in the paraxial mesoderm, has anterior neural-inducing activity

Shigeharu Yabe, Shunsuke Tazumi, Jun Yokoyama and Hideho Uchiyama Int. J. Dev. Biol. (2006) 50: 681-689

Comparative expression analysis of Pax3 and Pax7 during mouse myogenesis David Horst, Svetlana Ustanina, Consolato Sergi, Gregor Mikuz, Herbert Juergens, Thomas Braun and Eugene Vorobyov

Int. J. Dev. Biol. (2006) 50: 47-54

Distinctive expression of Myf5 in relation to differentiation and plasticity of newt muscle cells

Yutaka Imokawa, Phillip B. Gates, Young-Tae Chang, Hans-Georg Simon and Jeremy P. Brockes

Int. J. Dev. Biol. (2004) 48: 285-291

Murine tongue muscle displays a distinct developmental profile of MRF and contractile gene expression.

K R Dalrymple, T I Prigozy, M Mayo, L Kedes and C F Shuler Int. J. Dev. Biol. (1999) 43: 27-37

5 yr ISI Impact Factor $(2008)=3.271$

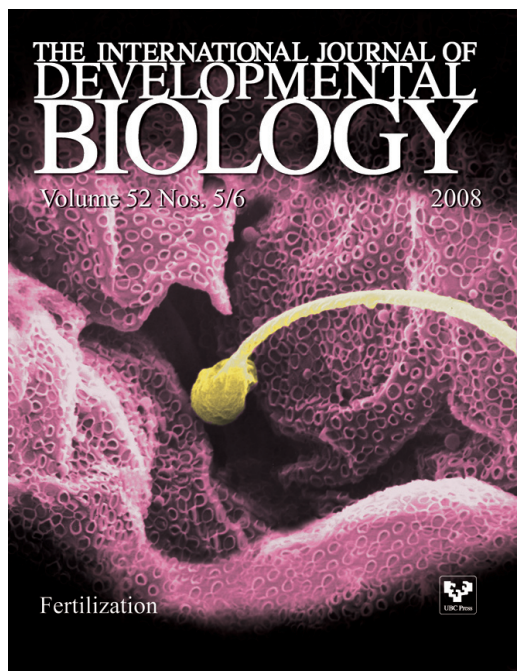

